Article

\title{
Assessing Hydrological Impacts of a Watershed in the Context of Climate and Land Cover Changes
}

\author{
Shih Dong-Sin ${ }^{1, *}$, Ray-Shyan $\mathrm{Wu}^{2}$ and Chung-Yuan Tsai ${ }^{2}$ \\ 1 Department of Civil Engineering, National Chung Hsing University, No 250 Kuokuang Rd., \\ Taichung 40227, Taiwan \\ 2 Department of Civil Engineering, National Central University, No. 300, Zhongda Rd., Zhongli District, \\ Taoyuan City 32001, Taiwan; raywu@ncu.edu.tw (R.-S.W.); joy79902@yahoo.com.tw (C.-Y.T.) \\ * Corresponding author: dsshih@nchu.edu.tw
}

\begin{abstract}
This paper proposes a method to utilize weather and land cover models to generate future environmental scenarios, and presents the watershed models to simulate the hydrological impact on watershed-scale hydrology. The Weather Generator model and General Circulation Model were applied to produce rainfall and local temperature under different climate conditions, and the Conservation and Land Use and its Effects model was incorporated to simulate future land cover variability. The circumstances of future climate and land cover changes were used as inputs to drive the HEC-HMS rainfall runoff model for obtaining surface runoff in a mountainous area. The WASH123D model was then utilized for the entire watershed simulation. Modeling results were then examined to discuss hydrological impacts on three different time periods: near future (20202039), future (2050-2069), and distant future (2080-2099). The Fengshan Creek basin in northern Taiwan was selected as study site. Simulations results indicated that the influence of climate change revealed more relevant effects when compared to local land cover changes. The ground water levels tended to diminish as the land cover area changed. In addition, both river and groundwater levels reveal that it is drier in dry season and wetter in wet season in future.
\end{abstract}

Keywords: climate change; land cover change; WASH123D

\section{Introductions}

Global climate change has been confirmed to result in worldwide raises to air temperature and heavy rainfall, to change in the temporal and spatial distribution of water resources, and to increase the occurrences of extreme rainstorms and drought (IPCC, 2008). Based on the Working Group I Contribution to the Fifth Assessment Report (AR5) of the Intergovernmental Panel on Climate Change, it shows a warming of 0.85 [0.65 to 1.06] ${ }^{\circ} \mathrm{C}$, over the period 1880 to 2012, when multiple independently produced datasets exist (Climate Change 2013, The Physical Science Basis, Summary for Policymakers, 2013). On the other hand, the intensity and frequency of heavy global rainfall are increasing and are bipolarized, meaning that rainy seasons are getting wetter, and dry seasons are becoming drier. Stream flow and groundwater recharge is particularly influenced during the wet and dry seasons. Average global extreme flood losses in 2005 are estimated to be approximately US $\$ 6$ billion per year, increasing to US $\$ 52$ billion by 2050 with projected socio-economic change (Hallegatte et al., 2013).

Climate change alters the risk of hydrological extremes at regional scales, and their hydrological response of a catchment can vary substantially not only due to its location but also depending on the characteristics of the catchments (Acreman and Sinclair, 1986; Beven et al., 1988; Veijalainen et al., 2010; Yan et al., 2015). Recent studies have concluded that climate change is evidenced to affect local rainfall amounts, surface runoffs and distribution of water resources (Akhtar et al., 2008; Arnell and Gosling, 2013; Guo et al., 2002; Kling et al., 2014). That is characterized by shifts in temperature and precipitation, which in response to their regions specific, e.g. alteration of extremes, intensities, 
frequencies, spatial and temporal patterns (Easterling et al., 2000; Hay et al., 2011; Hovenga et al., 2016; Wang et al., 2013). Hovenga et al., (2016) addressed the effects of climate change on overland processes, river inflow, and sediment loading for the Apalachicola region. Within the wet seasons, the A1B scenario had the largest loadings and A2 was typically largest during the dry season. To the same region, Chen et al. (2014) pointed seasonal response of runoff and sediment loads was slight with contrasting behaviors from different models.

In Taiwan, statistical data shows that the warming rate is $0.14{ }^{\circ} \mathrm{C}$ per ten years, from 1911 to 2009 (Climate Change in Taiwan: Scientific Report 2011). This increase in temperature is higher than the global average. In recent decades, extreme typhoon-induced floods occurred all over Taiwan. The rising sea levels induced storm surge, seawater intrusion, and even land salinization, all of which affect our living environment (Hsu et al., 2015; Shih et al., 2012b). To confront the effects of climate change in the future, land use planning has become one of the most important challenges facing Taiwan. One of the strongest influences on Taiwan's hydrological environment resulting from climate change is the impact of water resource distribution (Tung, 2001). Besides, extremely heavy rainfall results in flood-related disasters in low-lying areas, and worsens debris flow disasters due to hillside debris avalanches (Shih et al., 2012b). On the other hand, a decrease in medium- and low-intensity rainfall may lead to insufficient water content in the soil and in groundwater, resulting in a drought scenario. Therefore, variation in hydrological environments influences the stability of water supply, and can result in difficult scheduling and an undersupply of water resources.

In order to further discuss the effects of climate and land cover changes, future scenarios were generated using the Weather Generator (WGEN) model, General Circulation Models (GCMs), and the Conversion of Land Use and its Effects over Small Regions model (CLUE-s). The Hydrologic Modeling System (HEC-HMS) was applied to simulate runoffs, and the flow condition in a watershed is simulated using WASH123D (WAterSHed Systems of 1-D Stream-River Network, 2-D Overland Regime, and 3-D Subsurface Media) numerical models. Recent studies have indicated that climate scenarios generated from General Circulation Models (GCMs) or Reginal Climate Models (RCMs) are one of the most common approaches to estimate future flows (Déqué et al., 2007; Menzel et al., 2006; Minville et al., 2008; Prudhomme and Davies, 2008). Regarding the CLUE-s land cover modeling, applications which ranges from small regions to entire continents were conducted (Britz et al., 2011; Lin et al., 2007; Hurkmans et al., 2009; Park et al., 2011; Trisurat et al., 2010; Verburg et al., 2006; Verburg et al., 2006; Wassenaar et al., 2007). To watershed models, HEC-HMS is selected as the most appropriate protocol to conduct rainfall runoff simulation because it is also the most popular wieldy used and free model available. The model has been proved to be a reliable and usable for many hydrological simulations (Halwatura and Najim, 2013). WASH123D model has been applied worldwide in many projects, e.g. CERP and REMER projects. It has been chosen by the U.S. Army Corps as the core computational code to model the Lower East Coast (LEC) wetland watershed (Yeh et al., 2011). A newly revamped WASH123D model has been developed and applied to many of the river basins in Taiwan for the purposes of disaster reduction (Shih and Yeh, 2011; Shih et al., 2012a; Shih et al., 2012b; Hsu et al., 2015). Therefore, a modeling procedure was established to link above climate and land cover changes with watershed models in this study. In addition, the simulation results are examined to study the variability of the stream flow and groundwater level during the near future period (2020-2039 years), the future period (2050-2069 years), and the distant future period (2080-2099 years).

\section{Methodology}

In this study, various models were applied in order to examine different environmental scenarios. These approaches were introduced in detail in the following section.

\subsection{Weather Generator Models and Land Cover Change Model}

The WGEN model was applied to estimate future precipitation and temperature in this study. Weather generators based on either Markov chains (Richardson, 1981) or empirical distributions of 
wet/dry spells (Semenov and Brooks, 1999) are commonly used. This study used the Taiwan Climate Change Projection and Information Platform (TCCIP) to extract A1B scenarios from a special report on emission scenarios to model future scenarios (TCCIP, 2015). Temperature is simulated by using monthly mean and daily records, and assuming their properties base to first-order Markov Chain process (Pickering et al, 1988; Wu and Haith, 1993). Daily temperature is expressed as the function of monthly mean and standard deviation, and a random variable was used to generate an extraordinary occurrence. Rainfall event identification is determined based on historical rainfall probability. The Markov chain process, using historical records and a random variable, are applied to identify a rainfall event. First, it is determined whether a day is rainy or rainless, and then the amount of rainfall is estimated if rainfall occurs. An exponential distribution is utilized to estimate the amount of rainfall when a rainfall event is identified. As a result, near future (2020-2039 years), future (2050-2069 years), and distant future (2080-2099 years) scenarios are generated.

The CLUE-s model presents the probability of land use change in a region calculated by its spatial statistics. The method computes the land use change by considering socioeconomic and biophysical driving factors, based on system theory. The model can be used to predict the change in land conditions in designed scenarios. The CLUE model which allows scale and context specific specification for regional applications is also considered as one of most flexible, generic land use modeling framework (Verburg et al., 2002).

\subsection{HEC-HMS and WASH123D Models}

The HEC-HMS rainfall runoff model was used to generate discharges for WASH123D modeling, and then the variability of the river and ground water levels within the watershed-scale hydrology were discussed in the context of climate change. The HEC-HMS rainfall runoff model is a hydrologic model used for simulating the rainfall runoff process. The model was developed by the Hydrologic Engineering Center, U.S. Army Corps of Engineering (USACE, 2000 and 2008), which has three modules: the basin module, the meteorological module, and the control specification module (USACE, 2000). The parameters in these modules must be determined in advance in order to implement the rainfall runoff simulations. In this study, the Soil Conservation Service (SCS) Curve Number method was used to calculate the sub basin loss of the basin module. Therefore, the parameters of initial loss, $\mathrm{CN}$ (Curve Number) value, and impervious percentage of study area were regressed based on field measurements. The SCS Unit Hydrograph Method is applied to calculate sub basin routings, and the lag time of discharge is calculated by the statistics of historical records. Regarding the meteorological module, the HEC-HMS provides multiple options for indicating the rainfall distribution in the basin. This study used the rainfall station weighting method and provided the weights of various sub watershed control rainfall stations based on Thiessen polygons. The control specification module sets the time interval for the simulations, in which the $15 \mathrm{~min}$ and $1 \mathrm{~h}$ intervals are commonly used.

The WASH123D numerical model is utilized to study the variability of river and ground water levels. The watershed system is conceptualized as a 1-D river network, 2-D overland region, and 3-D subsurface media. The model was developed to cover dendritic river/stream/canal networks, overland regime, and subsurface media, including the vadose and saturated zones originally by Yeh et al., (1998). The WASH123D numerical model is selected as the most appropriate protocol to conduct our hydrology research because it is designed to simulate the flow of various component systems or combinations of component systems that comprise a watershed. Moreover, it is also capable of simulating problems related to various spatial and temporal scales, as long as the continuum assumptions are valid. In order to conduct efficient simulations, the following equations are applied in this study: the cross section-averaged 1-D diffusive wave equation, the depth-averaged 2-D diffusive wave equation, and the 3-D Richards equation. The equations are solved with semiLagrangian and Galerkin finite element methods to determine canal network flow, overland flow, and variably saturated subsurface flow (Yeh et al., 2011). Adequate data regarding initial conditions are obtained either from measurements or simulations of steady-state versions for the boundary settings. 


\section{Study Site and Model Configurations}

This section includes the introduction of the study sites, modeling configurations, and computational procedures. The details are followed.

\subsection{Study Site}

The Fengshan Creek basin was selected as the test site for this study, shown in Fig. 1. The site is favored because it is located in the Hsinchu County of Taiwan, where one of the most important science park is inside. Over the past few decades, the hillside in this area has been subjected to an excessive number of land reclamations and golf course construction, in which there are currently six golf courses with covering 310 hectares in area. Therefore, heavy rains have induced flash floods and inundations have resulted in significant damages to local populations. The Fengshan Creek originates from the Najie Mountain at an altitude of 1,320 m. Its trunk stream is approximately $45.45 \mathrm{~km}$ long, and the catchment area is $250.1 \mathrm{~km}^{2}$. The basin contains mostly hills with a flat area around $38.52 \mathrm{~km}^{2}$, and the average gradient of the river course is approximately $1 / 650$. The Fengshan Creek basin exists in a subtropical monsoon climate with an average temperature of $22.5^{\circ} \mathrm{C}$. It experiences typhoons during summer, and dry northeast monsoon weather during autumn and winter. Based on historical statistics, the average annual rainfall ranges from $1,754 \mathrm{~mm}$ to $2,715 \mathrm{~mm}$, and annual runoff is 376 million cubic meters.

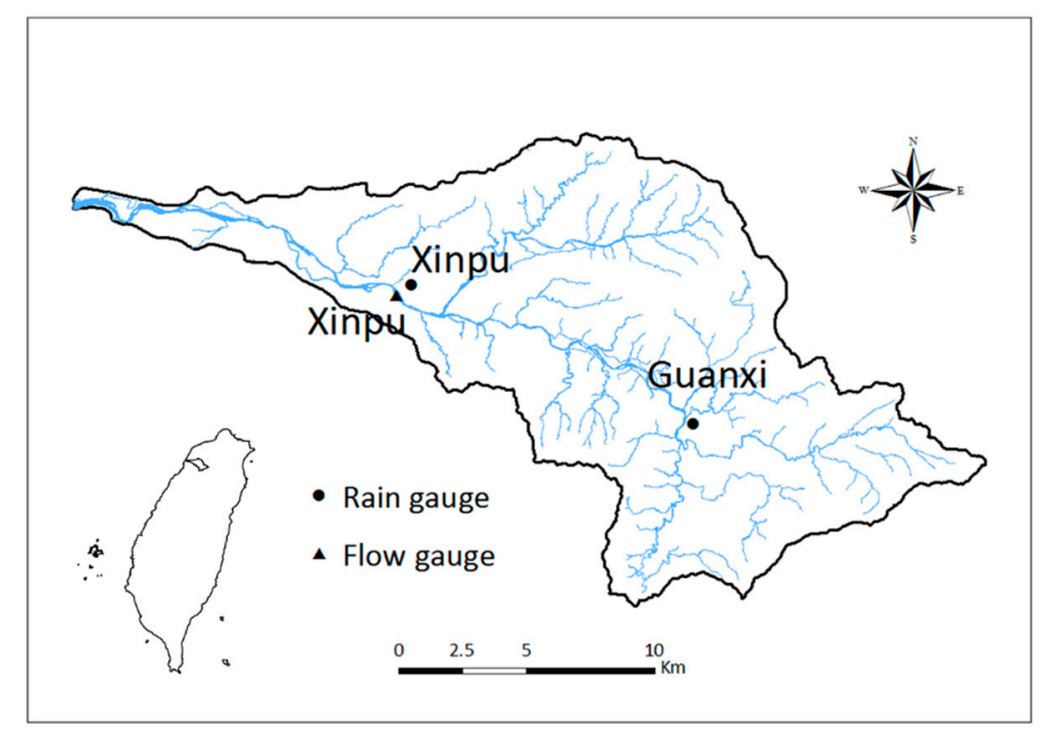

Fig. 1. Fengshan River basin

More than 30 years of rainfall records (1980 to present) collected by the Xinpu and Guanxi stations are adopted in this study. Flow measurement of the Xinpu Bridge station since 1970 provided from the Water Resources Agency, Ministry of Economic Affairs, Taiwan (WRA) is used. The latest land use map is obtained from the National Land Surveying and Mapping Center, Ministry of Interior, Taiwan (NLSC). It is classified into six land usage groups, and the proportion of land use to Fengshan River basin is listed in Table 1. The agricultural and forest areas represent the largest coverage areas in the watershed, accounting for $76 \%$ of the overall watershed area. The elevation of the Fengshan Creek basin ranges from sea level to around 1, $200 \mathrm{~m}$ in the mountainous region. The surface elevation is not only steep along mountainous region, but also very sharp along the Fenshan Creek. The surface elevation and its hillside gradient (right) of the Fengshan River basin is shown in Fig. 2. 

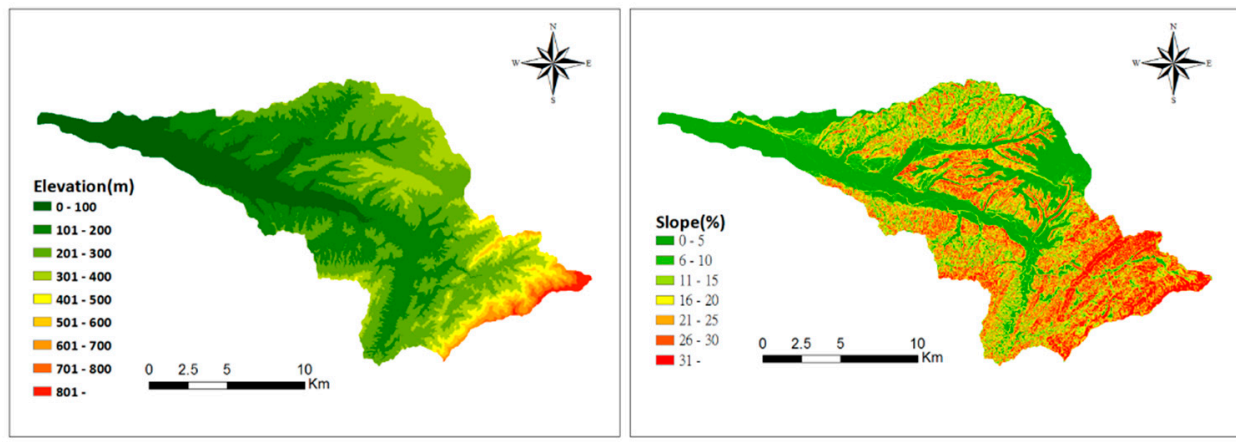

Fig. 2. Surface elevation (left) and hillside gradient (right) of the Fengshan Creek basin

Table 1. Status quo land use of Fengshan Creek basin

\begin{tabular}{ccccccc}
\hline & Agricultural & Forestry & Traffic & Water & Buildings & Other \\
\hline Area $\left(\mathrm{km}^{2}\right)$ & 57.3 & 133.8 & 8.8 & 7.8 & 15.9 & 27.6 \\
Percentage & $22.8 \%$ & $53.3 \%$ & $3.5 \%$ & $3.1 \%$ & $6.3 \%$ & $11.0 \%$ \\
\hline
\end{tabular}

Table 2. Scenarios of land cover change using Clue-s

\begin{tabular}{ccccc}
\hline & Scenario 1 & Scenario 2 & Scenario 3 & Scenario 4 \\
\hline $\begin{array}{c}\text { Development } \\
\text { Non-metropolitan areas }\end{array}$ & 77.42 & $\begin{array}{c}\text { Forest hillside } \\
\text { conservation area }\end{array}$ & $\begin{array}{c}\text { Average } \\
\text { slope }>30 \%\end{array}$ & $\begin{array}{c}\text { Non-city } \\
\text { reduced by 25\% }\end{array}$ \\
$\begin{array}{c}\text { (\%) } \\
\text { Metropolitan areas (\%) }\end{array}$ & 13.59 & 13.45 & 77.49 & 58.11 \\
Other regions (\%) & 8.99 & 9.09 & 13.44 & 32.81 \\
\hline
\end{tabular}

\subsection{Modeling Configurations}

The HEC-HMS model is used to estimate discharges from zones A and B of the mountainous regions of the Fengshan Creek basin, shown on Fig. 3. Then, the WASH123D model was applied to implement flow routing, including the river, overland, and subsurface of the watershed. The modeling environment of the one-dimensional (1-D) river was constructed using cross sections taken from field geometry, which is investigated by the Water Resource Agency of Taiwan (Second River Management Office). There are a total of 82 elements and 81 nodes built into the 1-D model. Twodimensional (2-D) surface grid settings utilize non-uniform meshes, which are constructed with a total of 6,134 grid points and 11,819 triangular surface elements. The triangular prism meshes for the three-dimensional (3-D) groundwater used 2-D grid as its surface layer. And the core data of different well sites (taken from Central Geological Survey, MOEA, Taiwan) are applied to divide 3-D groundwater layers. There are 30,670 grids, 59,095 elements, and 5 layers in total which comprise the underground grids. Fig. 3 shows simulation grid of the Fengshan Creek basin. 


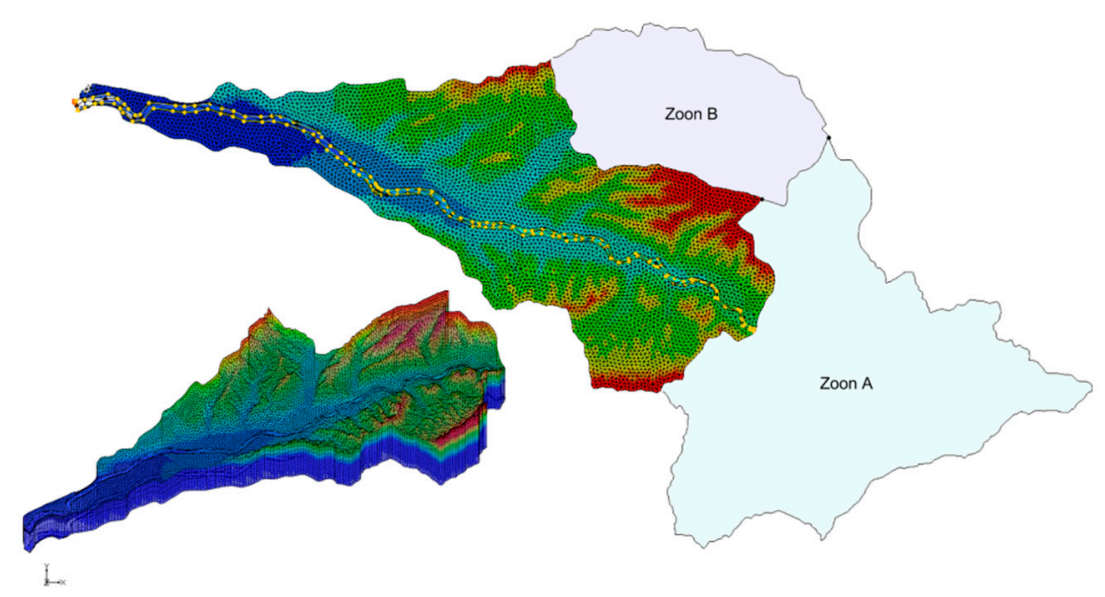

Fig. 3. Modeling zoon (A and B) in HEC-HMS and grid construction diagram of WAH123D

In order to better understand the hydrological impacts of this study site, four land cover scenarios for the year 2031 were simulated using the CLUE-s model. The land use transit map is based on investigations from year 1995 through 2007, in which the latest data in this site. Four scenarios are: (1) completely unrestrained development, which means future site development behavior is based entirely on current city growth. (2) hillside forest conservation as a space-constrained development area, so the urbanization is more apparently. (3) the constraint of building development when the average slope is greater than $30 \%$, which indicates that city development concentrates on the metropolitan area. (4) the agriculture and forest areas are developed up to $25 \%$, that is an extreme case where the agriculture and forest areas are developed up to $25 \%$, $(\mathrm{Wu}, 2014)$. These scenarios are listed in Table 4. Above scenarios were then taken into watershed routing in following.

\section{Result and Discussion}

This section discusses in detail the contents of the model calibrations and validations. Two most common used error indicators were applied to adjust parameters and evaluate modeling performance: $\mathrm{R}$-squared $\left(R^{2}\right)$, and root mean square errors (RMSE). Then, the hydrological impact under flash flood and long term influences are discussed in the context of climate change.

\subsection{Model Calibration and Validation}

HEC-HMS and WASH123D were applied for watershed routings. In order to determine the appropriate modeling parameters, a whole month from June $1^{\text {st }}$ to June 30 3 nd $^{\text {of }} 2011$ was examined to adjust Manning's coefficient $(N)$ and Hydraulic conductivity $\left(K_{s}\right)$. Another extreme event which lasted from July $31^{\text {st }}$ to August $02^{\text {nd }}$ of 2012 (Typhoon Saola) and one month period in which from May $1^{\text {st }}$ through May 31 ${ }^{\text {st }}$ of 2012, were applied to validate WASH123D modeling performance. The simulated parameters of the HEC-HMS model, included initial loss, curve numbers, non-infiltration areas, and runoff lag time, were determined based on the geographic properties of their statistic regressions. The curve numbers and non-infiltration covers which calculated via HEC-HMS are determined by land cover survey data. Table 3 lists above HEC-HMS model parameters of study site. The Manning's coefficients applied in WASH123D calculations on the channel and the overland were calibrated by referring to field investigations (Second River Management Office, Water Resource Agency, 2013), previous literature (Shih et al., 2012a), and used trial and error adjustments to estimate the parameters. In order to simplify the simulations, the Manning's coefficients of land surfaces were determined based on the soil type. They are classified into three categories: (1) non-metropolitan areas, which are mainly comprised of land used for agriculture and forests, (2) metropolitan areas, which are mainly comprised of buildings and non-infiltration regions, and (3) others, which include the land used for water conservancy, military affairs, and ore-bearing rocks. The study combined 
surface and groundwater simulation to calibrate the saturated hydraulic conductivity $\left(K_{s}\right)$ of the groundwater in the subsurface medium. The soil retention curves for the unsaturated zone are generated by the power-law related model, and assumed that the saturated hydraulic conductivity of the 3D subsurface flow in which the horizontal direction is 10 times to the vertical direction (Shih et al., 2012a). Values range from $10^{-3}$ to $10^{-8}$. These parameters are shown in Table 4.

Table 3. HEC-HMS modeling parameters of Fengshan Creek basin

\begin{tabular}{ccccc}
\hline & Initial loss (mm) & CN(I) & $\begin{array}{c}\text { Non-infiltration } \\
\text { covers (\%) }\end{array}$ & Lag time (min.) \\
\hline Zone A & 4.0 & 57.9 & 17.6 & 131.2 \\
Zone B & 4.0 & 61.1 & 22.1 & 147.2 \\
\hline
\end{tabular}

Table 4. Parameters used in Fengshan Creek basin of WASH123D model

\begin{tabular}{ccc}
\hline Channels (1-D) & Surface land (2-D) & Groundwater Layers (3-D) \\
\hline Mn & Mn & Ks $(\mathrm{m} / \mathrm{s})$ \\
& & Gravel $\left(1 \times 10^{-3}\right)$ \\
& Metropolitan areas $(0.120)$ & Mud or fine silt $\left(4 \times 10^{-6}\right)$ \\
$0.36 \sim 0.29$ & Non- metropolitan areas $(0.280)$ & River sediment $\left(2 \times 10^{-5}\right)$ \\
& Other $(0.085)$ & Aquifers $\left(1 \times 10^{-3} \sim 1 \times 10^{-5}\right)$ \\
& & Impermeable layer $\left(1 \times 10^{-8}\right)$ \\
\hline
\end{tabular}

The simulation results of the modeling calibration linking the HEC-HMS and WASH123D models reveal reasonable outcomes when compared to the water observation stage and groundwater levels, illustrated in Fig. 4. To further discuss discharges, this study selected the period from June 10 to June $13^{\text {rd }}$ in which extreme rainfall occurred to study. Fig. 4 (a) shows simulated flow peak nearly aligned with observations, and showed agreement on rising and recession limbs of hydrograph to the records. Research outcomes reveal that $R^{2}$ is over 0.9 which indicates that the simulated and observed data have high positive correlations. Essentially, the closer the $R^{2}$ is to 1 , the high accurate the model is. In addition, value for $R M S E$ is around $0.2 \mathrm{~m}$, which implies that the average modeling errors are very small. Fig. 4 (b) reveals simulated groundwater levels match the measured observation very well. The $R^{2}$ and RMSE is 0.747 and $0.102 \mathrm{~m}$ respectively. For a long term simulation, above groundwater results also perform well. The modeling settings of all parameters were fixed, and model validation was then conducted. Plots of the simulated flow patterns compared to observed data are shown in Fig. 5, in which the $R^{2}$ and RMSE is 0.964 and $0.101 \mathrm{~m}$, respectively. The simulations reveal very minor inconsistencies with the observations on the rising and receding limbs, shown on Fig. 5 (a). The modeling results also match the measured flow peak very well. Fig. 5 (b) is simulated groundwater level, which matches the measured observation very well. Therefore, it can be concluded that these parameters used in the hydrological models are suitable. 

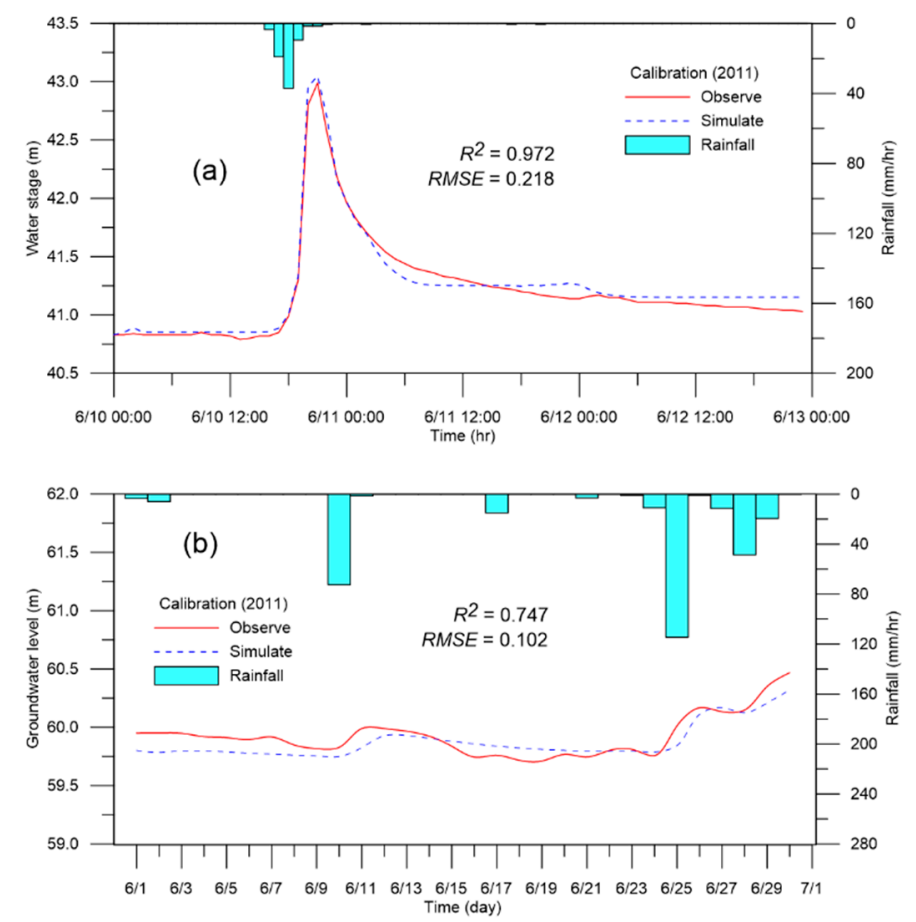

Fig. 4. Calibration results of (a) river water stage and (b) groundwater levels
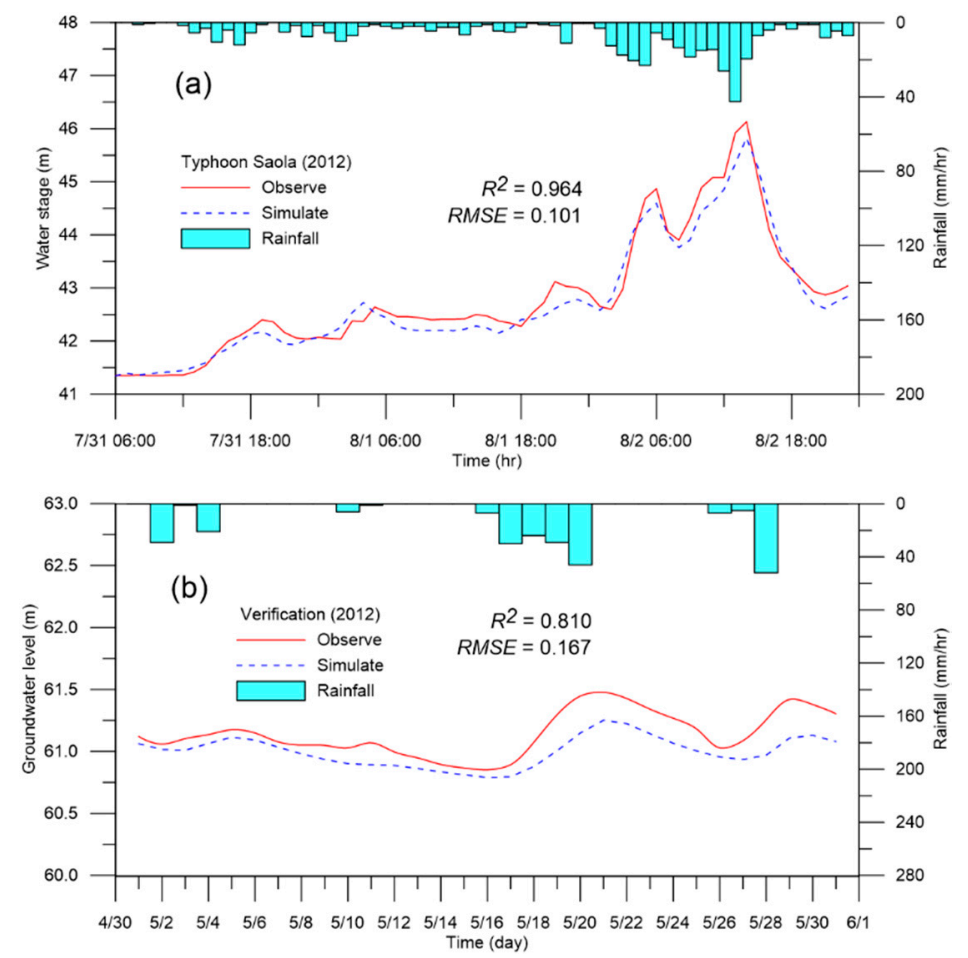

Fig. 5. Validation results of (a) river water stage and (b) groundwater levels

\subsection{Simulations of Climate and Land Cover Changes}

To further discuss the hydrological impacts on river levels in the future land cover changes, hydrological routings with four scenarios generated by the CLUE-s model were conducted. The study selected an extreme event, Typhoon Soulik ravaged through Taiwan from July $12^{\text {th }}$ to July $14^{\text {th }}$ of 2013 , to study. Simulated river stages of above four scenarios with compared to status quo land coverages are shown in Fig. 6. The simulations indicate that the results of the first three scenarios have a very similar pattern when compared to the original circumstances. Only the recession part of hydrograph shows the slight higher under land cover changes. However, scenario 4 revealed an apparent 
difference particularly on the flow peak increased and earlier raising limb occurrence. This is because the variability of the metropolitan area land coverage during past decades has no extensively growth. Only some local developments have been conducted. Therefore, it is clearly indicated that land coverage changes slightly in these first three scenarios. Further to check the simulation of surface inundations, results shows that the surface flooded area is mainly located in the main channel and the high bottom phase of the river. The flooded areas in Scenarios 1 to 3 are approximately identical. In Scenario 4, the flooded areas along the river course and their high bottom phase is getting enlarged. The simulation results for the first three scenarios show that the land use changes slightly influence the river water level. Only a drastic land use change has a significant effect on the water level, as shown in Scenario 4. In short, except extensively areal development is conducted in Fengshan creek basin in the future, otherwise there is no apparent stream flow varies as land cover changes.
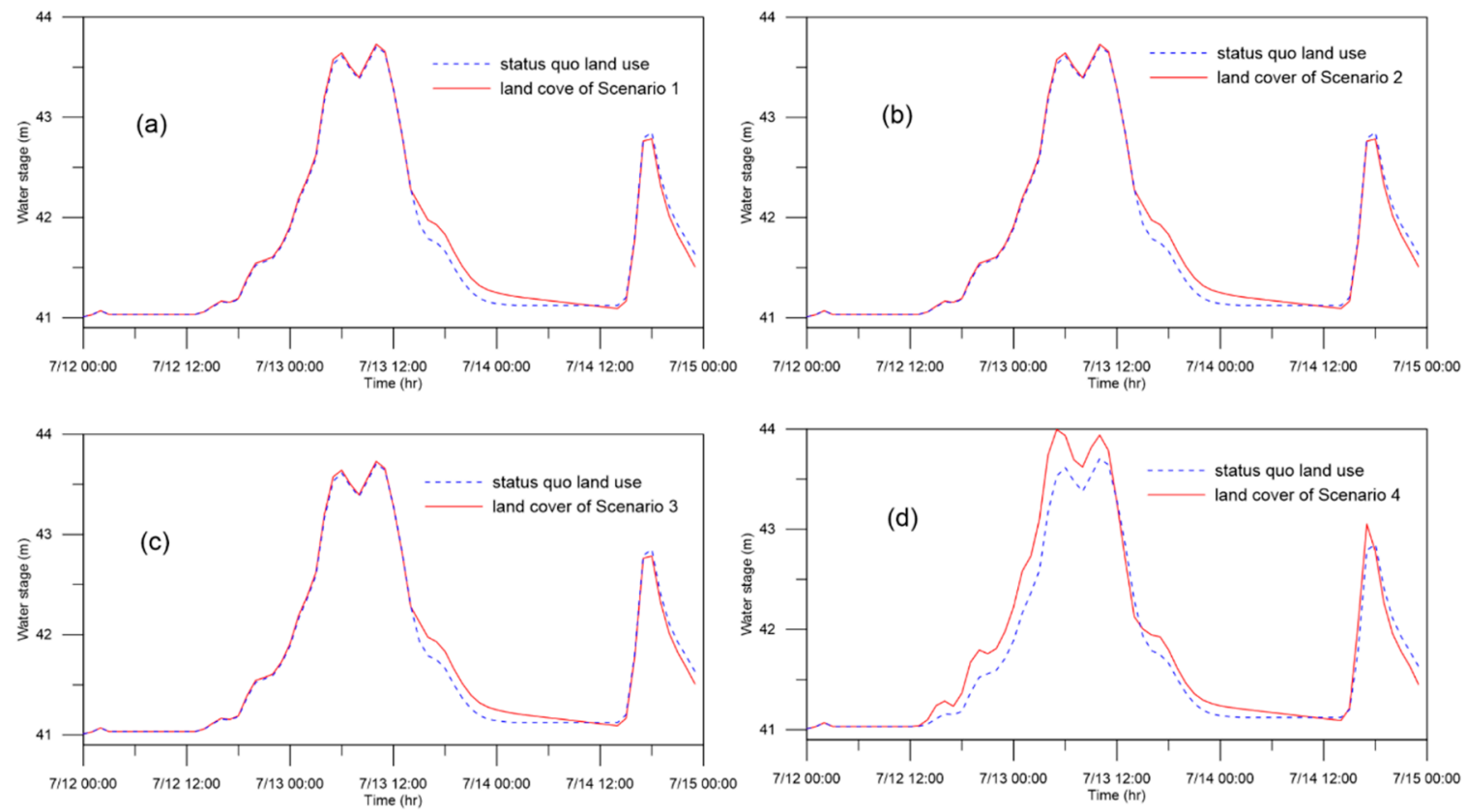

Fig. 6. River stages in four land cover scenarios

Scenarios of future climate change with land used changes have been simulated to discuss the long term variability of groundwater levels. In order to focused on Fengshen Creek basin, future land cover change uses an average of scenarios 1 to 3 from the above section. Modeling results of different climate scenarios (near future, future and distant future) all shows an increasing trend for river levels in future land covers. Mean monthly river level increase vary minor in average about $0.10 \mathrm{~m}$, as shown in Fig. 7 (a). Generally speaking, the wet season in Taiwan lasts from May to October, where the simulations imply that the water levels in the future scenarios are higher than in the status quo simulations. It is further indicated the mean monthly river level are reduced by $0.6 \mathrm{~m}$ in the dry season, and increased $0.15 \mathrm{~m}$ in wet season in Taiwan. Calculation of river level variability has been expressed in percentage, illustrated in Fig. 7 (b). It can be more apparently seen that water stage is became wet in the wet season and getting dry in the dry season. The simulations of dry season were contrary to the wet season results. In summary, the future land use with various future climate changes do not have a large influence on the water level of the river. However, the variance in the dry and wet seasons has a more obvious divergence on the increasing amplitude of the river water level. 

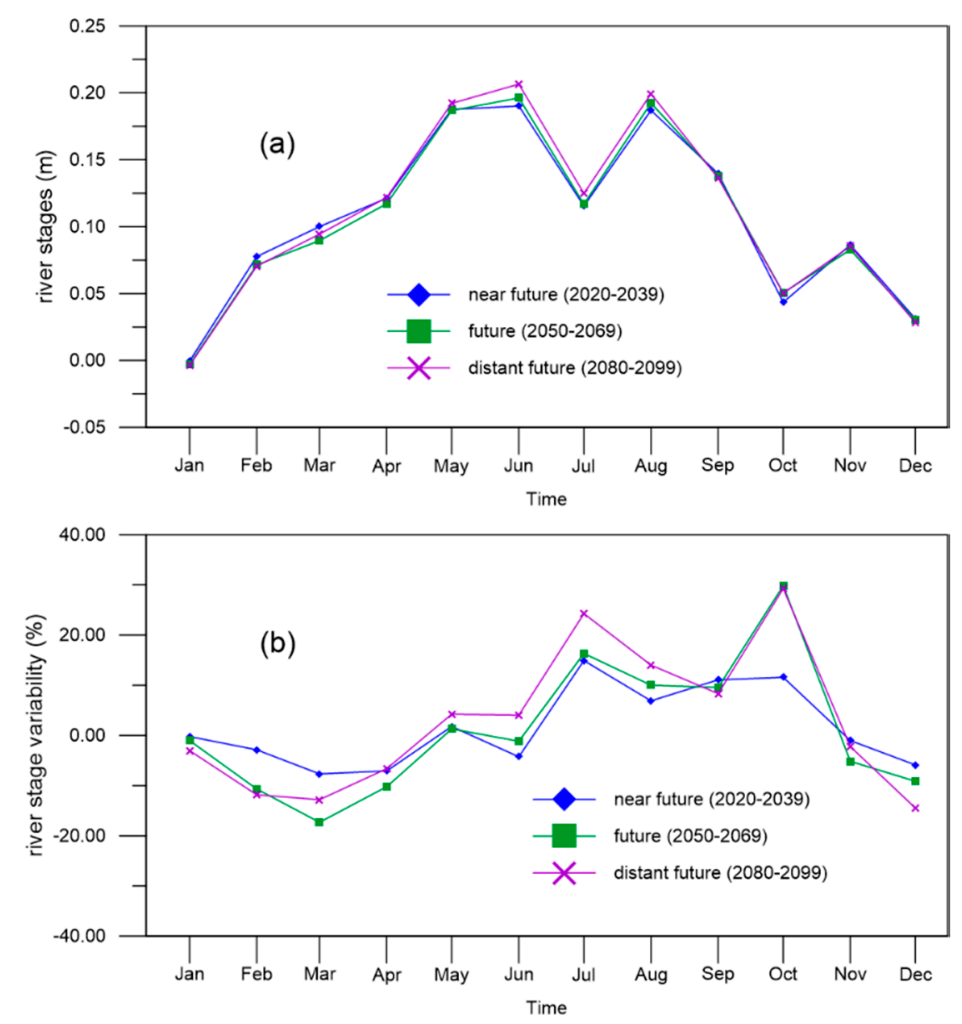

Fig. 7. Modeling results in future land cover and climate scenarios for (a) river stage and (b) their variance percentage

Simulations were then conducted for future climate and land use changes to study groundwater variability. Groundwater level variability and it variance percentages are shown in Fig. 8. Mean monthly groundwater level increase in average about $0.60 \mathrm{~m}$ in the dry season and $1.2 \mathrm{~m}$ in the wet season, as shown in Fig. 8 (a). To compare to status quo groundwater levels, their variance with different climate scenarios (near future, future, and distant future) in the dry season was reduced 9.69 $\%, 17.71 \%$, and $20.40 \%$, respectively, and increased $1.30 \%, 3.23 \%$, and $7.99 \%$ in the rainy season, as shown in Fig. 8 (b). In summary, groundwater level reveals a slightly increasing trend in future climate and land cover changes of Fengshen Creek basin. However, it tends to result in a decrease in groundwater level in dry season and increased in the wet season. Besides, simulations indicate that the hydrological change is mainly influenced by the climate change than land cover changes in this study. 

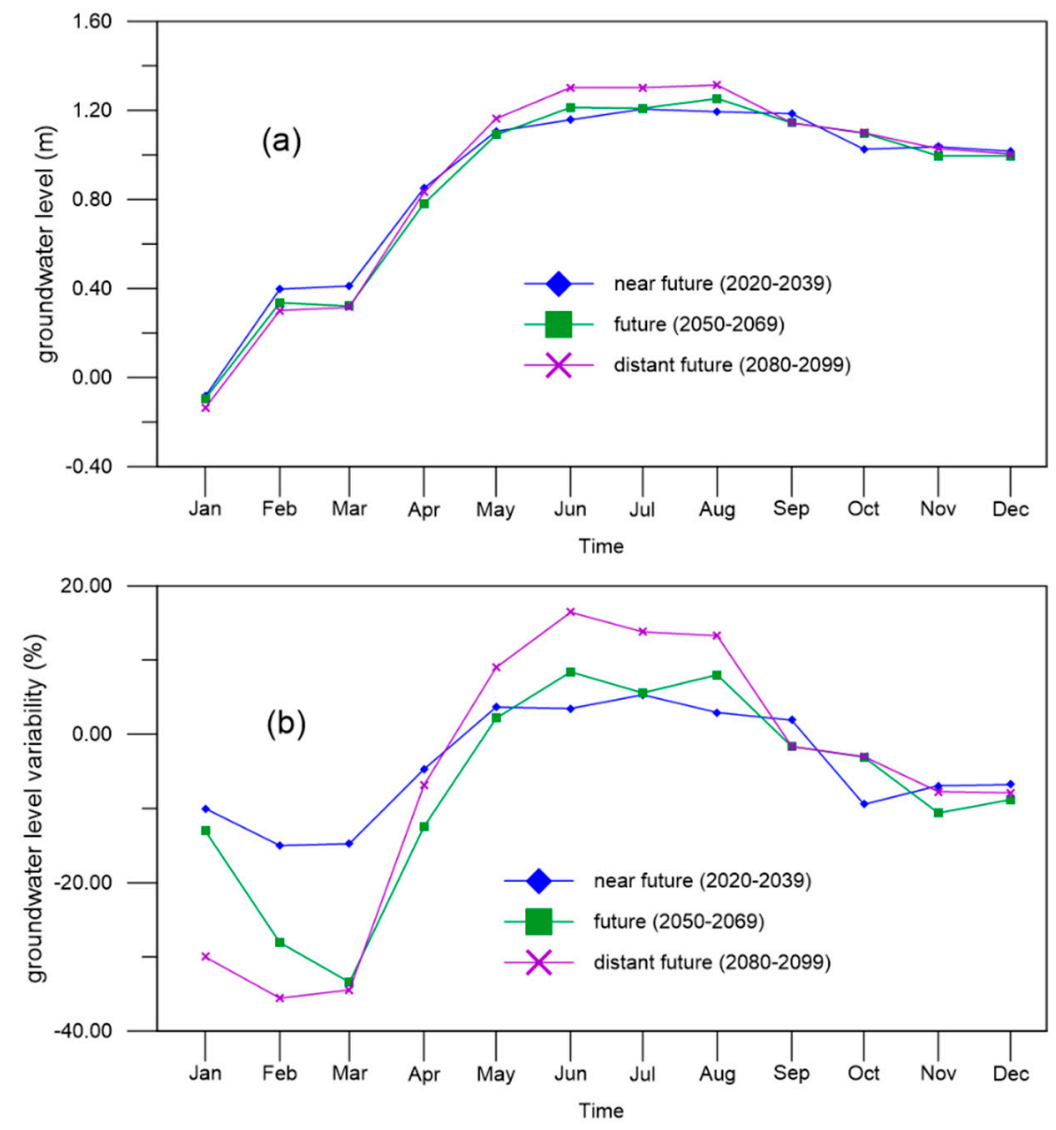

Fig. 8. Modeling results in future land cover and climate scenarios for (a) groundwater levels and (b) their variance percentage

\section{Conclusion}

This study proposed a method for linking the modeling of climate changes, land use changes, and hydrological impact to examine future environmental scenarios. The modeling procedure incorporated WGEN and GCM models to generate meteorological data, a CLUE-s model to predict land cover changes, an HEC-HMS rainfall runoff model to conduct discharges of watershed, and a WASH123D model to simulate hydrological variability within watershed-scale hydrology. The Fengshan Creek basin was used as the test case for this study. Simulation results indicated that land use changes have a very minor influence on the water level of the river and the surface runoff under extreme rainfall. Both river stage and groundwater level tend to slightly increase in the future scenarios. In addition, groundwater levels reveal that it is drier in dry season and wetter in wet season. Based on an evaluation of the simulations, the effect of land use change on the increasing amplitude of river water level and groundwater level is greater than the effect of the land use changes in Fengshen Creek basin. This indicates that, based on a comparison between climate change and land change scenarios, the hydrological change is mainly influenced by the climate change in this study.

Acknowledgements: This research is founded by the Ministry of Science and Technology, Taiwan, under Grant no. MOST-104-2621-M-005-007.

\section{Reference}

1. Akhtar, M., Ahmad, N., and Booij, M., J. 2008. The impact of climate change on water resources of Hindukush-Karakorum-Himalaya region under different glacier coverage scenarios. J. Hydrol. 355(1-4), 148-163.

2. Arnell, N. W., and Gosling, S.N. 2013. The impacts of climate change on river flow regimes at the global scale. J. Hydrol. 486, 351-364. 
3. Britz, W, Verburg, P. H., and Leip, A. 2011. Modelling of land cover and agricultural change in Europe: Combining the CLUE and CAPRI-Spat approaches. Agriculture, Ecosystems E Environment. 142(1-2), 40-50.

4. Chen, X., Alizad, K., Wang, D., Hagen, S. C. 2014. Climate change impact on runoff and sediment loads to the Apalachicola River at seasonal and event scales. J. Coastal Res., 68, 35-42.

5. Déqué, M., Rowell, D. P., Lüthi, D., Giorgi, F., Christensen, J. H., Rockel, B., Jacob, D., Kjellström, E., de Castro, M., van den Hurk, B. 2007. An intercomparison of regional climate simulations for Europe: assessing uncertainties in model projections. Clim. Change. 81, 53-70.

6. Easterling, D. R., Meehl, G. A., Parmesan, C., Changnon, S. A., Karl, T. R., and Mearns, L. O. 2000. Climate extremes: observations, modeling, and impacts. Science, 289(5487), 2068-2074.

7. Guo, S. L., Wang, J. X., Xiong, L. H., Ying, A. W., and Li, D. F. 2002. A macro-scale and semi-distributed monthly water balance model to predict climate change impacts in China. J. Hydrol. 268 (1-4), 1-15.

8. Hallegatte, S., Green, C., Nicholls, R. J., Corfee-Morlot, J. 2013. Future flood losses in major coastal cities. Nature Climate Change, 3, 802-806.

9. Halwatura., D., and M.M.M. Najim. 2013. Application of the HEC-HMS model for runoff simulation in a tropical catchment. Environmental Modelling \& Software, 46, 155-162.

10. Hay, L. E., Markstrom, S. L., Ward-Garrison, C. 2011. Watershed-scale response to climate change through the twenty-first century for selected basins across the United States. Earth Interact., 15(17), 1-37.

11. Hovenga, P. A., Wang, D., Medeiros, S. C., Hagen, S. C., and Alizad, K. A. 2016. The response of runoff and sediment loading in the Apalachicola River, Florida to climate and land use land cover change. Earth's Future, 4, 124-142.

12. Hsu, T. W., Shih, D. S., and Chen, W. J. 2015. Destructive Flooding Induced by Broken Embankments along Linbian Creek, Taiwan, during Typhoon Morakot. Journal of Hydrologic Engineering (ASCE), 20(7), 050140251 05014025-9.

13. Hurkmans R. T. W. L., Terink, W., Uijlenhoet, R., Moors E. J., Troch P. A., and Verburg, P. H. 2009. Effects of land use changes on streamflow generation in the Rhine basin. Water Resources Research, 45(6), W06405.

14. IPCC. (2008). Appendix A to the principles governing IPCC work. Procedures for the preparation, review, acceptance, adoption, approval and publication of IPCC reports. Intergovernmental Panel on Climate Change (IPCC). http://www.ipcc.ch/organization/organization_procedures.shtml.

15. IPCC. (2013). Summary for Policymakers, In: Climate Change 2013: The Physical Science Basis. http://www.ipcc.ch/report/ar5/wg1/.

16. Kling, H., Stanzel, P., and Preishuber, M. 2014. Impact modelling of water resources development and climate scenarios on Zambezi River discharge. J. Hydrol.: Reg. Stud., 1, 17-43.

17. Lin, Y. P., Hong, N. M., Wu, P. J., Wu, C. F., and Verburg, P. H. 2007. Impacts of land use change scenarios on hydrology and land use patterns in the $\mathrm{Wu}-\mathrm{Tu}$ watershed in Northern Taiwan. Landscape and Urban Planning, 80(1-2), 111-126.

18. Menzel, L., Thieken, A. H., Schwandt, D., and Bürger, G. 2006. Impact of climate change on the Regional hydrology - Scenario-based modelling studies in the German Rhine catchment. Nature Hazards. 38, 45-61.

19. Minville, M., Brissette, F., and Leconte, R. 2008. Uncertainty of the impact of climate change on the hydrology of a Nordic watershed. J. Hydrol. 358(1-2), 70-83.

20. Park, J.-Y., Park, M.-J., Joh, H.-K., Shin, H.-J., Kwon, H.-J., Srinivasan, R., and Kim, S.-J. 2011. Assessment of MIROC3.2 HiRes Climate and CLUE-s Land Use Change Impacts on Watershed Hydrology Using SWAT., American Society of Agricultural and Biological Engineers, 54(5), 1713-1724.

21. Pickering, N. B., Stedinger, J. R., and Haith, D. A. 1988. Weather input for nonpoint source pollution models. Journal of Irrigation and Drainage Engineering, 114(4), 674-690.

22. Richardson, C. W. 1981. Stochastic simulation of daily precipitation, temperature, and solar radiation. Water Resources Research, 17, 182-190.

23. Prudhomme, C., and Davies, H. 2008. Assessing uncertainties in climate change impact analyses on the river flow regimes in the UK. Part 2: future climate. Clim. Change. 93, 177-195.

24. Semenov, M.A., and R.J. Brooks. 1999. Spatial interpolation of the LARS-WG stochastic weather generator in Great Britain. Clim. Change. 11, 137-148. 
25. Shih, D. S., Liau J. M., and Yeh, G. T. 2012a. Model Assessments of Precipitation with a Unified Regional Circulation Rainfall and Hydrological Watershed Model. Journal of Hydrologic Engineering, 17(1), 43-54.

26. Shih D. S., Hsu, T. W., Chang, K. C., and Juan H. L. 2012b. Implementing Coastal Inundation Data with an Integrated Wind Wave Model and Hydrological Watershed Simulations. Terrestrial Atmospheric and Oceanic Sciences, 23(5), 513-525.

27. Shih, D.S., and Yeh, G.T. 2011. Identified model parameterization, calibration and validation of the physically distributed hydrological model, WASH123D in Taiwan. Journal of Hydrological Engineering, 16 (2), 126-136.

28. Taiwan Climate Change Projection and Information Platform. (2015). (TCCIP) webpage, http://tccip.ncdr.nat.gov.tw/NCDR/main/index.aspx.

29. Trisurat, Y, Alkemade, R, and Verburg, P. 2010. Projecting Land-Use Change and Its Consequences for Biodiversity in Northern Thailand. Environ Manag., 45, 626-639.

30. Tung C. P. 2001. CLIMATE CHANGE IMPACTS ON WATER RESOURCES OF THE TSENGWEN CREEK WATERSHED IN TAIWAN. JAWRA Journal of the American Water Resources Association, 37(1), 167-176.

31. US Army Corps of Engineers (USACE). (2000). Hydrologic Modeling System HEC-HMS: Technical reference manual. Hydrologic Engineering Center, Davis, CA - United States of America.

32. US Army Corps of Engineers (USACE). (2008). Hydrologic Modeling System HEC-HMS: Applications Guide. Hydrologic Engineering Center, Davis, CA - United States of America.

33. Veijalainen, H., Lotsari, E., Alho, P., Vehviläinen, B., and Käyhkö, J. 2010. National scale assessment of climate change impacts on flooding in Finland. J. Hydrol. 391(3-4), 333-350.

34. Verburg, P. H., W. Soepboer, A. Veldkamp, R. Limpiada, V. Espaldon, and S. SA Mastura. 2002. Modeling the spatial dynamics of regional land use: the CLUE-S model. Environmental Management, 30(3), 391-405.

35. Verburg, P. H., Witte, N., Schulp, C. J. E. and Veldkamp, A. 2006a. Downscaling of land use change scenarios to assess the dynamics of European landscapes. Agriculture, Ecosystems \& Environment, 114(1), 3956.

36. Verburg P. H., Overmars, K. P., Huigen, M. G. A., de Groot, W. T., and Veldkamp A. 2006b. Analysis of the effects of land use change on protected areas in the Philippines. Applied Geography, 26(2): 153-173.

37. Wang, D., Hagen, S. C., and Alizad, K. 2013. Climate change impact and uncertainty analysis of extreme rainfall events in the Apalachicola River basin, Florida. J. Hydrol., 480, 125-135.

38. Wassenaar, T., Gerber, P., Rosales, M., Ibrahim, M., Verburg, P.H., and Steinfeld, H. 2007. Predicting land use changes in the Neotropics: the geography of pasture expansion into forest. Global Environmental Change, $17,86-104$.

39. Wu, H. J. (2014). Application of Land Use Changes Model and Hydrological Model to Analyze the Impact of Hydrological Fluxes of Climate Change. Master's Thesis, Department of Civil Engineering, National Central University, Taoyuan. (in Chinese)

40. Wu, R. S., and Haith D. A. 1993. Land Use, Climate and Water Supply, Journal of Water Resources Planning and Management, 119(6), 685-704.

41. Yang, Y. C. E., Ray, P. A., Brown, C. M., Khalil, A. F., and Yu W. H. 2015. Estimation of flood damage functions for river basin planning: a case study in Bangladesh. Nature Hazards. 75, 2773-2791.

42. Yeh, G. T., Cheng, H. P., Cheng, J. R., Lin, J. H. 1998. A numerical model to simulate flow and contaminant and sediment transport in watershed systems (WASH123D). Waterways Experiment Station, Technical Rep CHL-98-15.

43. Yeh, G. T., Shih, D. S., and Cheng, J. R. 2011. An Integrated Media, Integrated Processes Watershed Model. Computers \& Fluids, 45(1), 2-13.

(C) 2017 by the authors; licensee Preprints, Basel, Switzerland. This article is an open access article distributed under the terms and conditions of the Creative Commons by Attribution (CC-BY) license (http://creativecommons.org/licenses/by/4.0/). 